\title{
Aesthetics in Structures
}

\section{Chandana Kulasuriya}

Abstract: This paper describes the fact that 'aesthetics of structures' is related to various aesthetic concepts, styles, movements, theories and also with the technical considerations. Further, it also describes that all the above-mentioned considerations have roots in the fundamental philosophical models of aesthetics. It also discusses the application of geometric theories and structural theories in achieving aesthetics of structures.

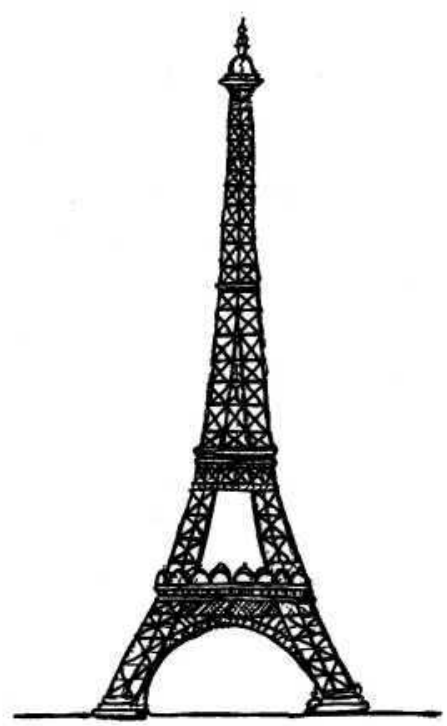

\section{Introduction}

Normally architects are responsible for aesthetics of structures. However, structural systems and structural components designed by the engineer play a major role in the aesthetic appearance of structures. For example the visual appearance of high-rise buildings mainly depends on the structural system. Similarly, the roof structure is a prominent visual element of many structures. Therefore, the engineer has the challenge of designing sub-structures like roof structure, supporting structure, etc., to achieve the architect's goal of aesthetics. In this exercise, if the engineer has the knowledge of basic aesthetics, he would be able to understand the architect's language easily and to design structural components to satisfy the architect's requirements. Further, if the engineer is aesthetically conscious, he would be able to develop totally new structural forms and help architects to design innovative structures.

Although most of the buildings are designed by architects, there are certain structures designed by engineers themselves. For example, structures like bridges, transmission towers, water towers, etc., are designed by engineers. Hence engineers should be responsible for aesthetic aspects of these structures. This responsibility can be fulfilled if the engineer has the knowledge of aesthetics and design.

The above mentioned facts confirm that the knowledge of aesthetics would be very useful for engineers not only to help architects to achieve their goals but also to design engineering structures such as bridges, towers, etc.

Within the discourse of 'aesthetics of structures', the 'structure' is considered as a three dimensional composition. Hence, before studying aesthetics of structures, certain fundamental concepts about composition have to be understood. Hence the first few paragraphs of this paper deal with that.

When 'aesthetics of structures' are concerned, it cannot be studied in isolation, as it has links with many other areas such as art, architecture, philosophy, engineering, history, etc. Therefore this discourse extends towards those areas as well.

\section{Nature of Aesthetics}

The word 'aesthetics' has been derived from the Greek word 'aesthesis'; meaning sensory perception. It was regarded as a branch of philosophy concerned with the understanding of beauty and its manifestation in art and nature. ${ }^{3}$ However, it is extremely difficult to give a precise definition for aesthetics. Aesthetic consciousness covers special sentiments, tastes, interests, concepts, ideals, views and theories.

Eng. Chandana Kulasuriya, BA-Fine Arts \& Philosophy, MEng. Struct. Eng., CEng., Chartered Civil Engineer, , MIE(SL),MCSA, Lecturer at Open University of Sri Lanka 
It is generally recognised that aesthetics has two components - 'emotional component' and the 'intellectual component'. It is believed that the emotional component is very much subjective and the intellectual component is less subjective. The motional component is an indefinable, intuitive aspect of our personality and it provides us the ability to emotionally appreciate an object. On the other hand, the intellectual component is considered as a rational aspect, and hence, it provides us the ability to rationally appreciate an object, considering the function of the object, constraints, specifications, conditions, etc.

Nevertheless, some philosophers who doubt the existence of 'so-called objectivity', question the validity of a 'so-called intellectual component'. According to them the 'so-called objectivity' is merely an 'inter-subjective agreement', among a particular group of people, based on certain views, assumptions, ideas, theories, standards, values, etc. Hence according to this view, aesthetic consciousness is both an intra-subjective andintersubjective agreement.

\section{Characteristics of A Composition}

Primarily, structures can be considered as three dimensional compositions. Therefore, it would be useful to study about compositions to understand the aesthetics of structures.

A 'Composition' can be described as an arrangement of parts or elements into proper relation to produce a conceptual unified whole. There are a number of approaches to study 'composition' ${ }^{\prime 20}$. However, the approach discussed in this paper is the 'principle of formal analysis' developed in the worlds of art and architecture which permit the description and investigation of our reactions to visual stimuli. The importance of this analysis is that it can be related to scientific study of perception.

\subsection{Fundamental characteristics of a composition}

Unity, balance, harmony, contrast, emphasis, movement, and rhythm are some of the fundamental characteristics of a composition. ${ }^{20}$
It seems unity, balance, harmony, rhythm, etc., are innate needs of us. This is related to our desire to understand and control our environment, and may be a part of our primitive survival skills. It may also be driven by basic emotions such as insecurity and fear of the unknown. ${ }^{20}$ However, the pure, perfect form of these characteristics can result in monotony or boredom. In view of that unity with variety, occasional discontinuity of rhythm, dramatic contrast can be used to make the composition interesting.

\section{Unity:}

Unity is the quality of 'singleness effect' and the 'completeness' of a composition. In a unified work of art, all the parts come together to form a 'unifiedwhole'; each part of a composition 'feels' like that it belongs with the rest. That is unity which refers to the visual linking of various elements of the composition. A designer achieves unity by balancing all the aspects of the composition.

When the eye is attracted by two stimuli of equal importance, the resolution of elements into a 'unified whole' is prevented or disturbed. This effect is known as 'duality'.

For example, when two objects which are spaced too far apart for the eye to see them as a unit, but not far enough apart for them to be perceived as completely independent, 'duality' can be experienced. However, this can be resolved by inserting a dominant central block between the two objects (Figure 1a). ${ }^{20}$

The same thing happens with bridges (Figure 1b) ${ }^{33} \mathrm{~A}$ single-arch bridge shown in the figure, though simple, is visually satisfying. However, when there are exactly similar arches next to each other, the eye finds it difficult to resolve it into a unified whole. Instead the eye looks at one span and then at the other. The eye goes to arches and not to the piers, and it will 


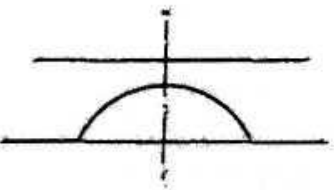

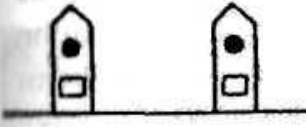

Duality

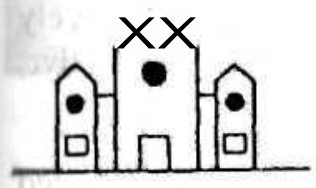

Unity

(a)
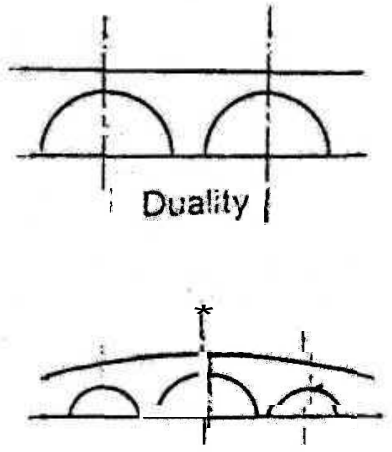

Unity

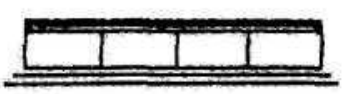

Unity

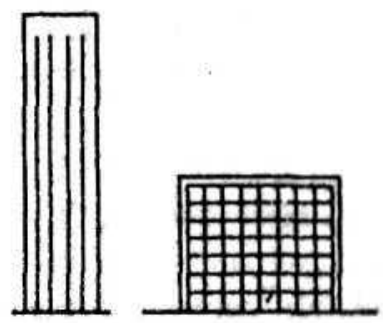

Unity Duality

(b)

(c)

Fig. 1 - Unity \& Duality

wobble from one centre-line to the other, so that $A$ feeling of restlessness is produced. However, this can be resolved by introducing a dominant central arch between the two arches. Here the centre-line is not only the centre-line of the middle arch but also that of the bridge; and the eye is in no doubt at all to decide the line upon which to concentrate. There is no question of it wobbling from one centre-line to another, and shows a composition of complete restfulness.

Duality may also be experienced when the facade of a building has equal horizontal and vertical emphasis (Figure 1c). ${ }^{21}$

When the eye is attracted by multiple stimuli of equal importance, a similar effect, which may be termed as 'multiplicity', can be experienced.

Normally 'Unity' is recognised as a basic requirement of a good composition. Hence 'Lack of unity', duality, multiplicity may be considered as a fault. However in certain periods people have exhibited impatience with the concept of unity and duality was advocated as a means of relieving the boredom of unity.

\section{Balance}

'Balance' can be described as a state of equilibrium between its elements. ${ }^{21}$ Balance in design is similar to balance in physics. Without it, the composition looks awkward and unstable.
The concept of balance is related to the 'visual centre of gravity' of an object and 'visual weights' of elements. The eye expects a 'balance' about the visual centre of gravity as though it were a fulcrum and the various visual weights applied with various leverages. The 'visual weight' of an element may be manipulated by delineation or varying the play of light and shadow to hint at solidity or hollowness.(Figure 2)

There are two types of balances, symmetrical and asymmetrical. Symmetrical balance is easier to understand. Symmetry is the balance of mirror figures about a point, line or plane. The usual emotional response to symmetrical balance is 'stability' or 'satisfaction with the status quo'. Asymmetrical balance sometimes referred to as Occult balance, is much more subtle, but it usually stimulates a dynamic and emotional response. Acceptable asymmetric balance depends largely on the emotional qualities of aesthetics and the personality of the designer and the viewer.

\section{Harmony}

Harmony in a composition is the visually satisfying effect of combining similar, related elements. The designer can create harmony through elements such as shapes, colours, textures, etc. (e.g. - Adjacent colours on the colour wheel create a feeling of harmony) 
(a)

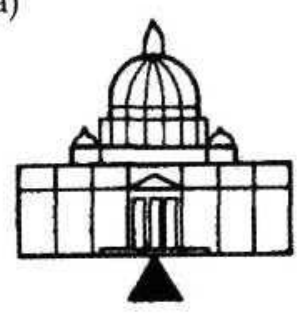

(b)

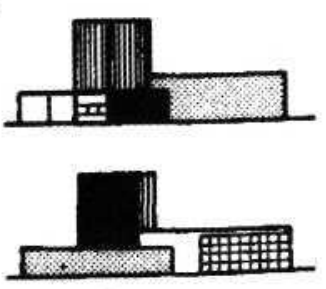

Fig. 2 - Symmetrical balance $\&$ Asymmetricalbalance

There are two kinds of harmony with respect to any object present in the environment - internal and external. Internal harmony refers to the relation between parts of the object, where as external harmony refers to the relation of the object to its surrounding environment.

Harmony gives a feeling of unity and coherence with associated psychological reactions of security and relaxation.

\section{Contrast}

Contrast is an abrupt, unexpected change in a visual element. The designer can create contrast through the elements such as shapes, colours, textures, etc. For example, complementary colours of colour wheel (red/green, yellow/ purple, blue/orange) seem to create a feeling of contrast when they are placed together in a composition.

\section{Emphasis}

As a composition develops a designer may decide to stress certain elements of the design over others to create a 'focalpoint'. The eye of the viewer will focus on the area of 'emphasis' or 'centre of interest' first, and then take in the rest of the composition. A designer uses emphasis to direct and focus attention of the viewer on the most important parts of a composition. A designer creates emphasis through size, colour, texture, and shape. A composition lacking emphasis will be monotonous and uninspired.

\section{Movement}

Movement is the way the viewer moves his eye around through the composition after seeing the 'focal point'. A designer arranges parts of a composition to create a sense of motion by using elements such as shapes, colours, textures, etc.

\section{Rhythm}

Rhythm is the regular repetition of elements of a composition to produce the look and feel of movement. A designer creates movement in a composition by repeating elements such as colours, shapes, lines, textures, etc. The repetition of the elements invites the eye to jump rapidly or glide smoothly from one image to the next. Rhythm allows the designer to create a feeling of organized movement. Elements placed at regular intervals create a calming rhythm. Sudden changes in position and size create a lively rhythm. Variety keeps rhythm exciting and active, moving the eye around the composition.

As the eye scans across a building it is affected by the regularity or otherwise of elements such as windows, mullions, columns, and arches which may give rise to an impression of 'rhythm'. Rhythms may be seen as slow and smooth when they are based on a few elements which are widely spaced relative to the overall form, or rapid and staccato. Rhythms may be read vertically as well as horizontally. ${ }^{20}$

\subsection{Other Qualities}

In addition to fundamental characteristics such as unity, balance, harmony, rhythm, etc., structures, may be associated with features such as identity, character, meaning, etc. ${ }^{20}$

\section{Identity}

Identity of a structure may be related to location, history, culture, society, etc. For example Pagodas have a Japanese Identity.

\section{Character}

Structures may have a character as in the case with human beings. For example a structure with a strong vertical emphasis may be seen as excuding pride, self-confidence.(Figure 3). Lighter constructions (Figure 4) may have an air of ethereality. 


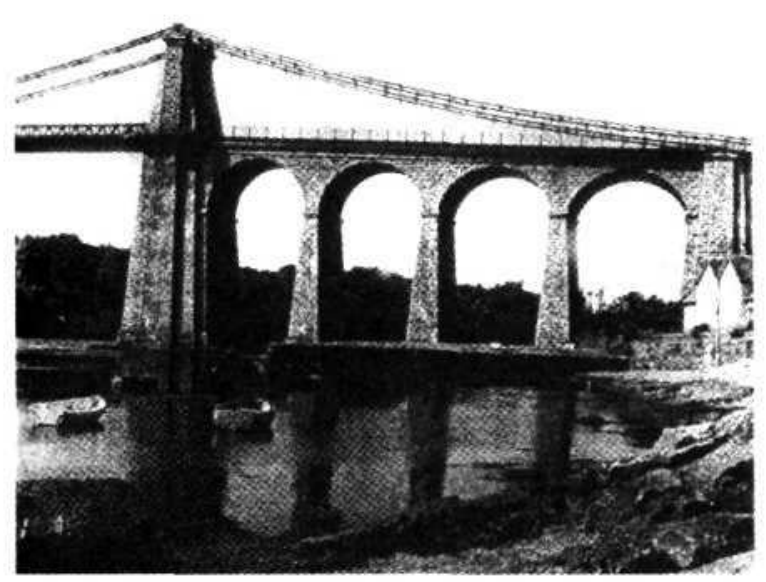

Fig. 3- Thomas Telford's Bridge ${ }^{33}$

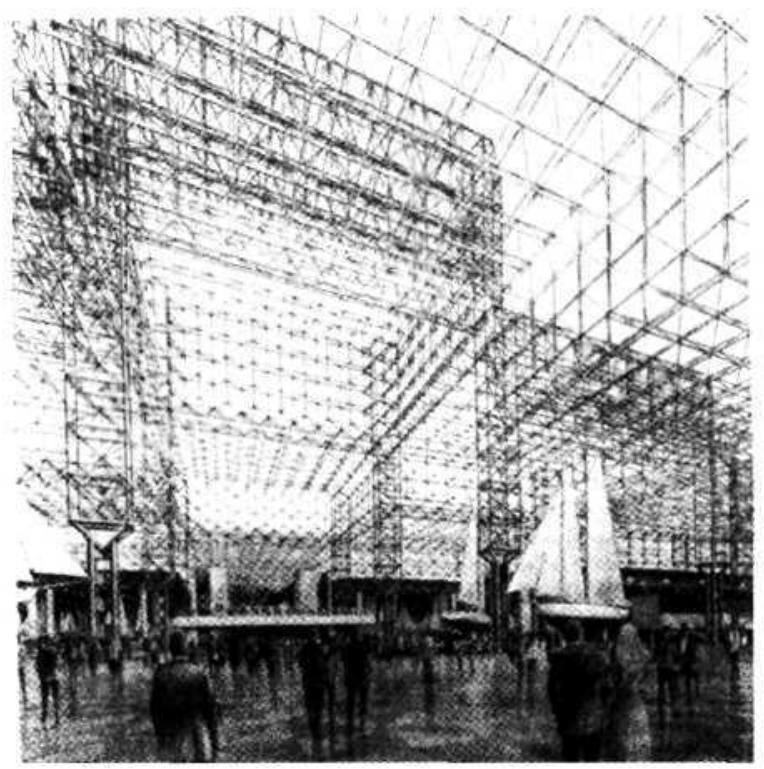

Fig. 4 - Convention Centre, New York ${ }^{33}$

\section{Meaning}

A structure may express its' function. For example the appearance of a hospital may reflect its' function.

In addition to the above mentioned characteristics, qualities like sensuality, tension, excitement, humour etc., too can be integrated to structures to create an interest. This can be done by the structure as a whole or by its' components in the form of 'innocentjokes', 'simplenonsense', 'pinchof insecurity', etc. For example an inverted pyramid-like structure may produce a sense of insecurity and a tension in the observer. Twisted shafts or hanging columns may produce a sense of humour in the observer.

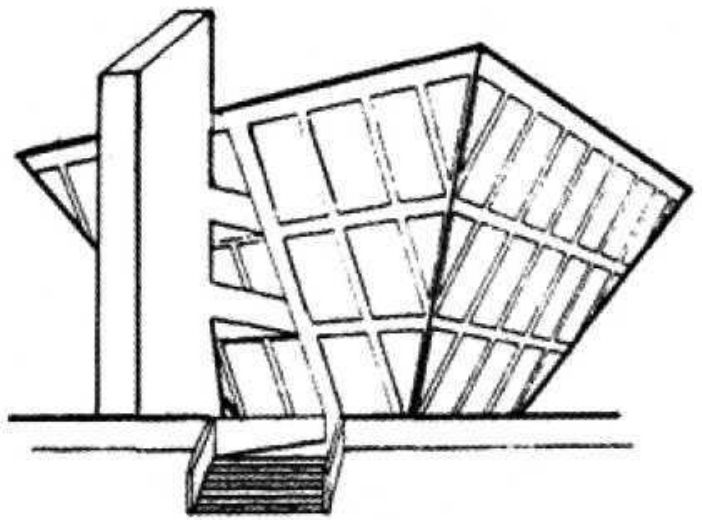

Fig. 4 - Inverted Pyramid-like building

\subsection{Elements of Composition}

The above mentioned characteristics or qualities are acquired by a three dimensional composition by some basic elements such as Size \& Scale, Form $\&$ Shape, Proportion, Space, Texture, Colour, Light $\&$ Shade, Visual weight, Pattern, Ornamentation etc.

\section{Aesthetic Concepts Related to Structures}

There are various concepts behind aesthetics of structures. These concepts are integrated to the structure not only by the designer but also by the critics, conservators, users, observers, etc. This can happen either at conscious or subconscious level of the person concerned. Some of such concepts that are integrated with the structures are given below.

"The structure should appear to spring naturally from its surroundings'

"The structure should harmonise with surrounding context."

"The structure need not necessarily harmonise with the existing surrounding context, the constructive conflicts between the structure and the existing surrounding context may create a new form of progressive aesthetics."

"Thestructure should resemble or suggest forms found in nature"

"The structural skeleton should be completely covered with aform giving skin (cladding), like in animals."

"Thestructure should be subjectivelyrelated with the consumer or the user"

"The structure should express its'function" 
"Thestructureshouldbeassimpleaspossible"

"The structureshouldbelike 'plug-incomponents' of aprinted electronic circuit board"

"The structure should be truthful / rational / honest aspossible"

These aesthetic concepts are reflected in many structures. Clustered water tanks at Alencon, France, look like trees in nature. (Figure 6a) This reflects the concepts related to 'organic forms'. The Eiffel Tower in Paris contradicted with the environment and the contemporary society, when it was first erected. However, later it was able to create new aesthetic values and became the 'semiotic symbol' of France (Fig 6b). This may reflect the concept of 'constructive conflicts'. Water Tower at Fisons Fertilizer Factory, UK, is subjectively related with the factory workers and

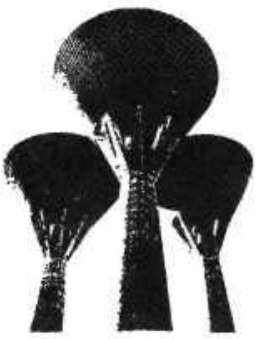

(a)

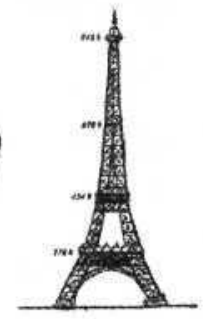

(b)

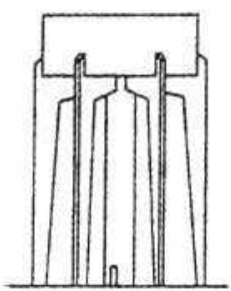

(c)

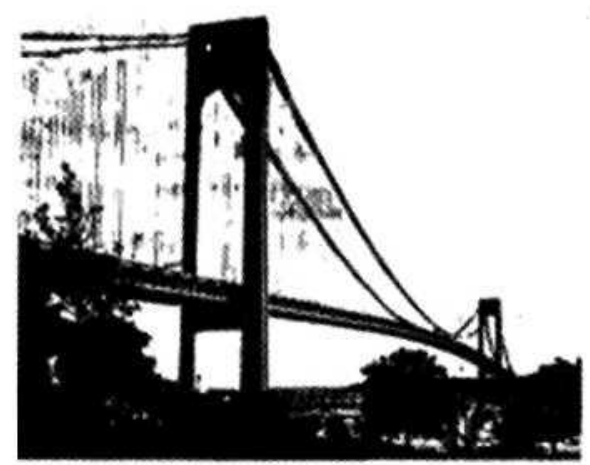

(d)

Fig. 6 - Reflections of aesthetic concepts in structures

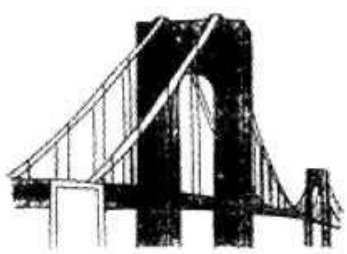

(a)

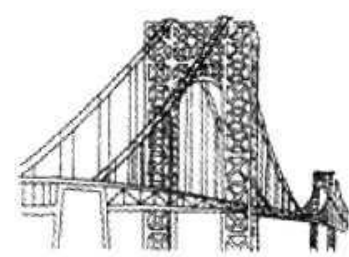

(b)
Fig. 7 - George Washington Bridge expresses the feeling of sharing the work (Figure 6c). Verrazano Narrow's Bridge is a completely truthful expression of a tensile material in the form of the 'funicular form' (Figure 6d) .This reflects the concept of 'truthful structures'.

The original design of the George Washington Bridge, New York, is a steel structure with a stone cladding (Figure 7a). This reflects the concept of 'form giving skin of animals'. However, after the structural skeleton was erected, it was not clad by stones despite the opposition of a large part of New York intelligentsia and the design engineer himself (Figure 7b). However, later, the aesthetics of the exposed structural skeleton has been widely appreciated by all. Here, the naked steel structure reflects the concept of 'honesty'. This indicates the rapid changes of aesthetic appreciation and also the different reflections of aesthetic concepts.

\section{Aesthetic Movements \& Styles Related to Structures}

Aesthetics of structures cannot be understood in isolation. It has a historical narrative. Within this historical narrative aesthetics has evolved through a number of movements. These movements have influenced the aesthetics of structures directly or indirectly. Therefore, aesthetics of a particular structure has to be understood within that background.

Aesthetics of structures have been influenced by the aesthetic movements. Rationalism, Arts and Crafts Movement, Art Nouveau, Cubism, Chicago School, Constructivism, Functionalism, Bauhaus, Expressionism, International Style, Brutalism, Organic architectural style, Art Deco, Vernacular Architecture, Modernism, Postmodernism, High-tech and Deconstruction are some of such movements. Some of them are briefly described below. ${ }^{8}$

\section{Constructivism}

A movement which originated in Moscow after 1917, primarily in sculpture but with broad application to architecture. The expression of construction was to be the basis for all building design. ${ }^{8}$

\section{Functionalism}

A design movement that evolved from several previous movements in Europe in the early $20^{\text {th }}$ century, advocating the design of buildings, 
furnishing, or the like as direct fulfilment of Iiuntional requirements, with the construction, materials, and purpose clearly expressed, and with the aesthetic effect derived chiefly from I MIportions and finished to the exclusion or subordination of purely decorative effects. functionalists believe that when function is fulfilled, the form will follow automatically 'I $\operatorname{mim}$ follows function'. ${ }^{8}$

\section{Ixpressionism}

I - pressionists rejected the hard, rectilinear and 'functional' standard boxes in favour of an individual and romantic approach. Buildings were meant to express or symbolise their use, bringing together form and content in a new I" risonal language. Symbols used were often those relating to speed and machines as well as being often consciously or subconsciously nexual. ${ }^{10}$

\section{Orutalism}

The term 'Brutalism' was derived from the French tim 'betonbrut which means rough concrete. Nermally concrete is surfaced plaster, but the Giutalists thought that, in the interest of honesty or authenticity, it should be exposed. Some buildings which do not show rough exposed in rete have also been classified as Brutalist. In these, an exposed steel frame is visible on the exterior. ${ }^{\mathrm{s}} \mathrm{s1}$

\section{Organic architectural style}

Amovement of architectural design thatemerged in Ilieearly $20^{\text {th }}$ century, asserting that a building should have a structure and plan that fulfil its functional requirements, harmonize with its hitural environment, and form an intellectually iwid, Integrated whole. The shapes or forms in wuih rt work are often of irregular contour and ieem to resemble or suggest forms found in nature. ${ }^{\mathrm{B}}$

\section{Modernism}

A deliberate philosophical and practical estrangement from the past in the arts and literature occurring in the course of the $20^{\text {th }}$ century and taking form in any of the various innovative movements and styles. ${ }^{8}$

\section{Post-modernism}

A movement in architecture and the decorative arts that developed in the 1970's in reaction to the principles and practices of modernism, especially. the influence of the International Style, encouraging the use of elements from historical vernacular styles and often playful illusion, decoration, and complexity. ${ }^{8}$

Post-modern architects have continued to take advantage of the new materials available while turning to differentperiods of the past for artistic inspiration. There has, for instance, been a revival of the principles of classical architecture with emphasis on proportion and harmony. This has even led to the design of supermarkets in the style of palaces, and offices in the style of temples. ${ }^{8}$

\section{High-tech}

A style of design incorporating industrial, commercial, and institutional fixtures, equipment, materials, or other elements having the utilitarian appearance characteristic of industrial design.

One way of achieving this is by ensuring that certain essential services, which are normally concealed within the building, are clearly visible from outside. Lifts travel up and down its front or sides. Escalators are suspended from the structure on to the exterior. Pipes for airconditioning and water are not only visible but are designed as decorative features. Bright colours predominate on the exterior. Pipe work may be colour-coded to indicate its various functions. All the structural parts may be in one distinctive colour or clad in stainless steel. ${ }^{8}$

\section{Deconstruction}

A critical movement that started in the 1960's, especially. in the study of literature, questioning traditional assumptions about the ability of language to represent reality and emphasizing that a text has no stable reference because words essentially refer only to other words. A reader must therefore approach a textby eliminating any abstract reasoning or ethnocentric assumptions through an active role of defining meaning, sometimes by a reliance on etymology and new word construction. ${ }^{8}$ 


\section{Aesthetics of Structures and Related Theories}

Through the centuries, since the Greeks first codified their ideas on aesthetics, many theories about preferences in the realms of art and architecture have been developed. These theories can be organised into four categories: geometric, rationalist, sculptural and structural. ${ }^{26}$

\section{Geometric Theory (Proportioning Theories)}

These theories are based on the idea that we find certain things or experiences beautiful because they resonate with patterns built into our cognitive systems. It is a common experience from music that certain combinations of sounds (chords) are generally judged to be beautiful, while others are considered dissonant, even uncomfortable, such as the sound of fingernails on a blackboard. Perhaps the fingernail sound causes our cells to vibrate in ways that disturb their functioning. ${ }^{26}$

Many of the classical theories of proportion trace back to this idea. Rectangles proportioned according to the 'Golden Ratio' (1:1.618) were considered automatically superior because they supposedly appealed to some inherent inner sense of visual proportion. (See Appendix 1). ${ }^{26}$

Through the history, the golden proportion has consistently brought a sense of harmony to design, not to mention a spiritual and even a physical sense of well being. A number of examples could be cited, including Stonehenge in England, in Egypt, classical temples of Greece, Gothic cathedrals and modern buildings. ${ }^{2}$ Some of these structures are presented in Appendix 2.

\section{Rationalist Theories}

This set of ideas states that we like objects whose shape clearly reflect its function. For example, a teapot with a comfortable handle and efficient spout will be more attractive than a teapot shaped without regard to these functional necessities. ${ }^{26}$

This theory applies more easily to objects with a single obvious function. Engineering structures such as bridges, water tanks, transmission towers, etc., fall clearly into this category. Buildings accommodating multiple functions are not as easily approached this way. ${ }^{26}$

\section{Sculptural Theories}

The goal of sculpture is to produce threedimensional objects which have the sole purpose of evoking emotions or reflecting ideas. These theories state that we like certain objects because their shapes evoke emotions or reflect ideas which accord with our needs or value systems. ${ }^{26}$

\section{Structural Theories}

These theories state that we like certain objects because they clearly reflect their structural behaviour. The theory assumes that we all possess an inherent understanding of structure, based on each person's struggle with gravity from the day we begin to walk. ${ }^{26}$

The cantilever is an example of this idea which applies to bridges. To most people a cantilever is more attractive if it is thicker at its support and tapers towards its free end. People find it attractive because it reflects the cantilevers they are already familiar with: the shape of their own arms and legs or the branch of a tree. From this familiarity people develop an intuitive understanding of what the engineer knows from calculation: that the stresses in a cantilever are largest at the support, and therefore that's where most of the material should be. ${ }^{26}$

\section{Philosophical Models of Aesthetics}

All the above mentioned aesthetic concepts, styles, movements, theories etc., have their roots at various philosophical models of aesthetics. These models are derived from fundamental paradigms of philosophy. Although these models do not directly reflect the philosophical paradigms, which they were derived from, they reflectcertaincharacteristicsofthoseparadigms. Naturalism, Objective Idealism, Subjective Idealism, and Materialism, are some of the major historical philosophical models of aesthetics. ${ }^{1}$

\section{Model of Naturalism:}

Aesthetics is a natural property of nature. Objects are perceived as aesthetic when they reflect properties (proportion, form, shape, etc.) that are found in nature. According to this model aesthetics is considered as a natural form.

\section{Model of Objective Idealism:}

Aesthetics is an objective quality, which is independent of and external to human 
сани iousness It is often associated with concepts ttml are considered' universal'. According to this modelrtWBthvticsis considered as an objective form, i universal form; an absolute form; an eIt mil form: a truthful form; a super-individual I иm dis ine form; etc.

\section{Medel of Subjective Idealism:}

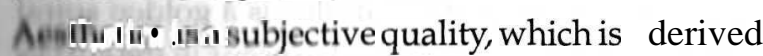
bouc. Ih h $\mathrm{u}$ m a $\mathrm{n}$ consciousness, whichis primary. Acurding to this model aesthetics is considered iti- isubjertive form; an individual form.

\section{Model of Materialism:}

Aeethetics is a property of phenomena and objects (matrili), which is a result of their relations with ..... ikind Those relationships may be harmenious, or conflicting (or dialectical). AMrerding to this model aesthetics is considered it a m itilal form; dialectical form; social form.

Helationship with philosophical models with ather concepts and theories

Al mentioned before, aesthetic concepts, mevements or styles, theories mentioned in the w.i. loum paragraphs have their roots in various philosop hital models of aesthetics. For example, aesilietif toncepts related to 'nature', 'organic - fi ....tural style', 'golden ratio' used in jegmetii theory, have their roots in the aesthetic 'me•lehot naturalism'. Aesthetic concepts related 'D Ifuihilui st nictures', 'technical considerations' inatruifural theories, 'honesty' in the movement af britalism, are related to the 'model of objective idealiam' Aesthetic concepts related to the 'user', me> ement sol functionalism, reflections of 'furblion' IIIrationalist theories are related to the 'meidel of subjective idealism'. Concept of '. Tanirutive conflicts', 'expression of e日esiruition' discussed in the movement of cอคดiruivism, are related to the model of dialectio il materialism.

Tii understanding of philosophical models of $\mathrm{ftM} \| \mathrm{n}<\mathrm{tlr}$ « would be helpful for any designer to icide the relevant aesthetic qualities to be integrated to the structure. Further, he would be able teronstruct new models of aesthetics. Based in these models new aesthetic concepts can be formulated and these concepts can be applied in designing struc lures.

\section{The Composition \& The Context}

A composition cannot be perceived in a vacuum. It has to be perceived with relation to the surrounding context. Structures too are considered as compositions in the environment. Accordingly, structures too are perceived with relation to the surrounding context. Therefore, aesthetic qualities of a structure too have to be appreciated within the surrounding context. For example, a particular bridge may harmonise with one environment but may conflict with another environment.

The designer's intention may be to make the structure harmonise or conflict with the surrounding context. Whatever it is, it could be realised only if the context is properly analysed and the structure is designed accordingly. Otherwise, the aesthetic outcome may be different than the expected one. Hence the word 'context' is very important.

\section{APPENDIX 1 - Golden Proportion ${ }^{2}$}

The 'golden proportion' is found when a line is divided into two unequal lengths so that the longer part relates to the shorter part as the whole length relates to the longer part. The ratio is identified by the Greek letter $\phi$, and it translates numerically to a ratio of $1.618: 1$.

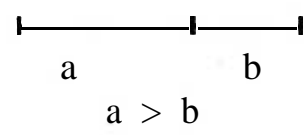

\section{Golden Rectangle and its Properties}

A rectangle whose sides are proportioned according to the golden ratio is known as the 'golden rectangle'. The golden rectangle is supposed to be the most visually satisfying of all rectangles.

A

D

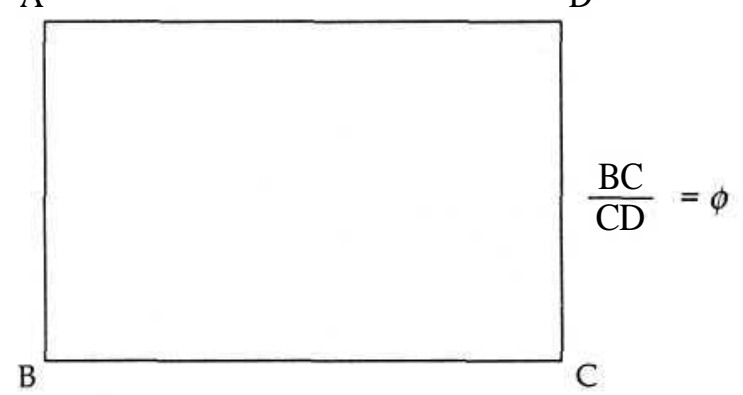

Fig.37 - Golden Rectangle 


\section{Properties of Golden Rectangle}

If a square is constructed on the smaller side of the golden rectangle, the remaining portion of the original rectangle would be a smaller but similar golden rectangle. This operation can be repeated indefinitely to create a gradation of squares and golden rectangles.

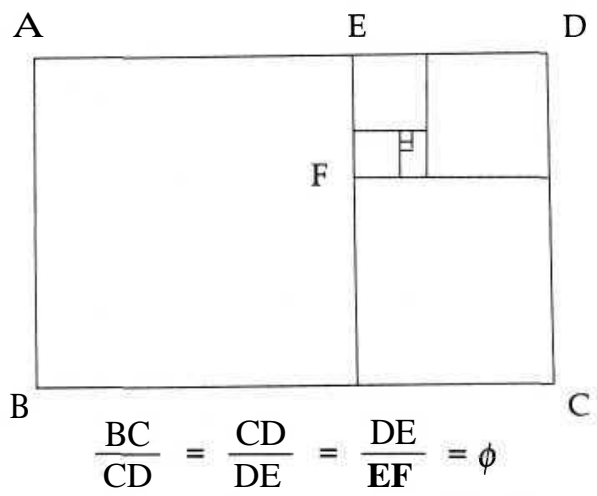

Fig. 38- Gradation of Squares \& Golden Rectangles

A series of arcs placed in the squares as shown in the Figure 39, give rise to a special spiral known as 'golden spiral'. This is also known as 'equiangular spiral' or 'logarithmic spiral'. This is the only spiral that does not alter shape as it grows. As shown in Figure 40, the curve of the spiral always intersects the outreaching radii at a fixed angle.

$$
\begin{aligned}
& \mathrm{a} / \mathrm{b}=(\mathrm{a}+\mathrm{b}) / \mathrm{a} \\
& \text { Let } \phi=\mathrm{a} / \mathrm{b} \\
& \phi 2-\phi-1=0 \\
& \phi=(1+\sqrt{5}) / 2=1.618
\end{aligned}
$$

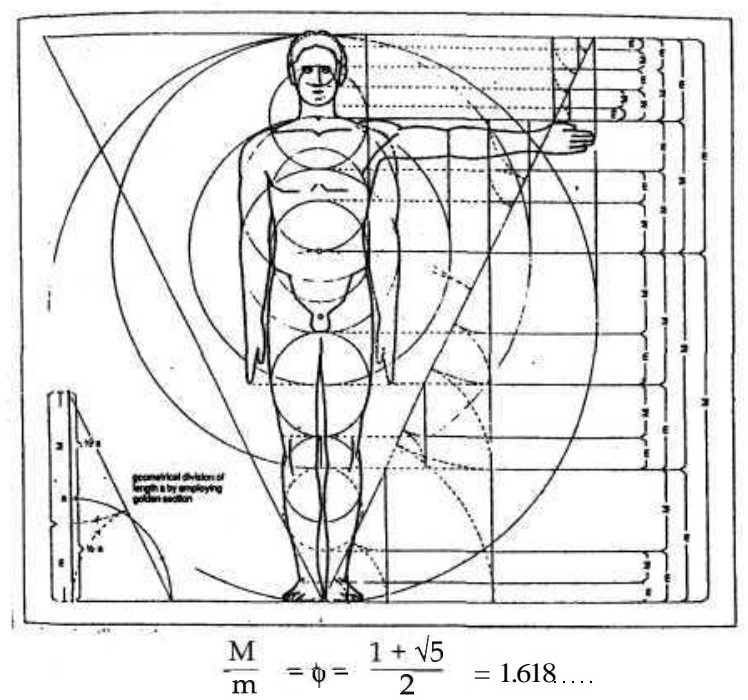

\section{Golden proportion in nature}

The golden proportion appears in nature constantly. Many of the proportions of the human body and some proportions of animals also conform to the golden ratio (Figure 41).

The golden spiral, which is derived from the golden rectangle too, appears in nature. The shape of the shell of the chambered nautilus is a golden spiral (Figure 42). Golden spirals also occur in the curves of elephants' tusks and in the horns of wild sheep. Similar, though less precise, spirals are formed by the florets in the core of daisy blossoms (Figure 43).

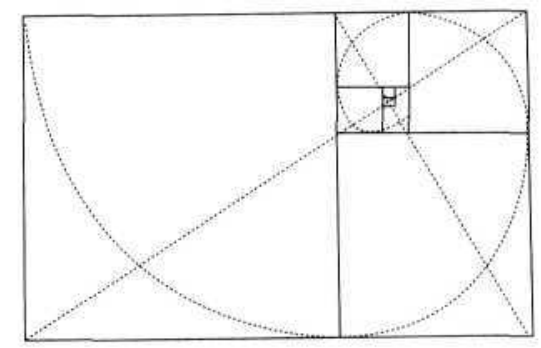

Fig. 39 - Golden Spiral

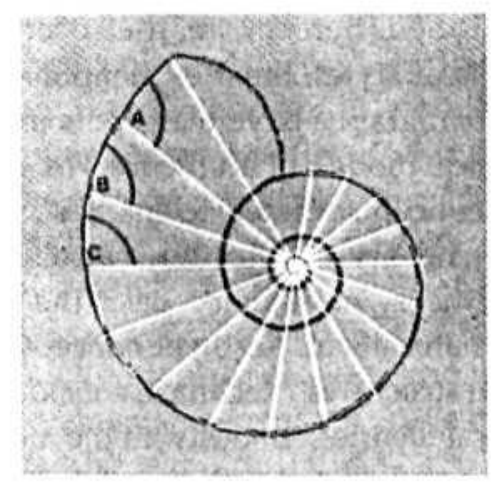

Fig. 40 - Intersection of curve and radii
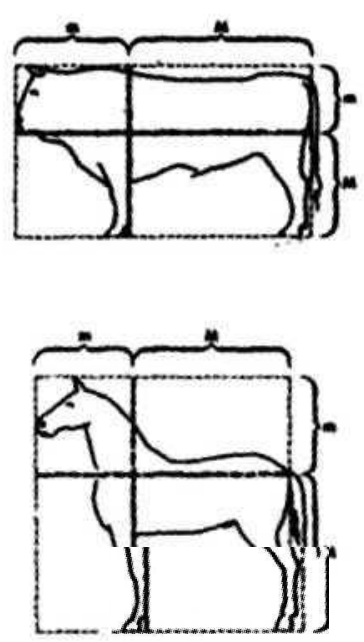

Fig. 41 - Golden proportions of the human body and of the animals 


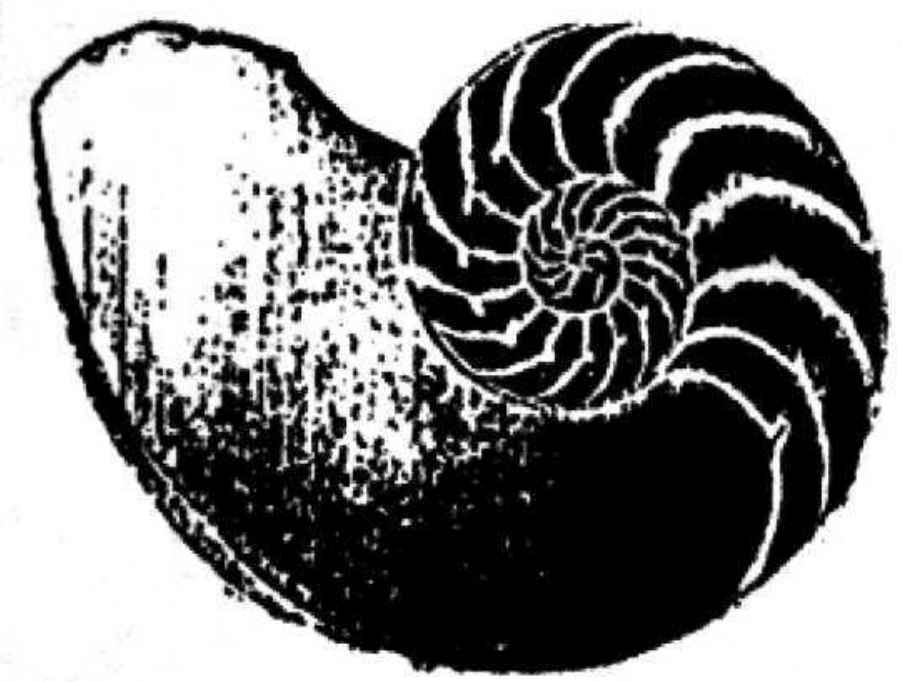

Fig. 42 - Golden spiral in Nautilus Shell
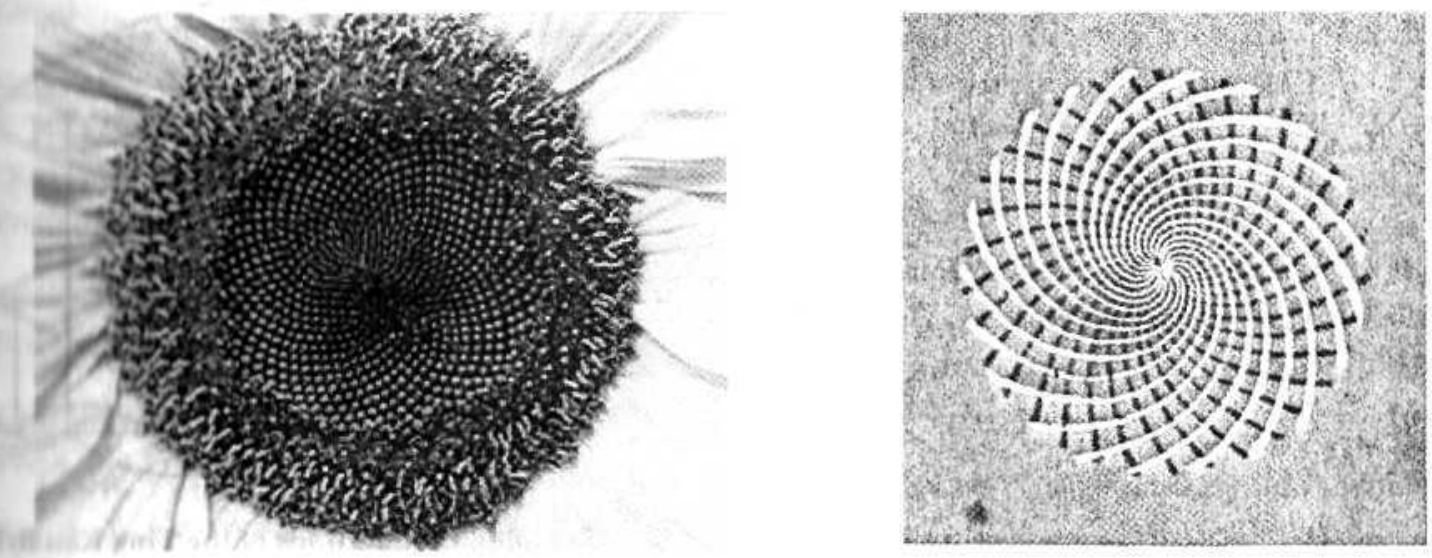

Fig. 43 - Golden spiral in daisy blossoms

\section{APPI NDIX 2 - Application of the - alaen Proportion in structures}

- Halic n proportion has been employed in aiructures through the centuries. Some of the iruetures are presented here, where the isperImposed curves pick out golden fripiputions.

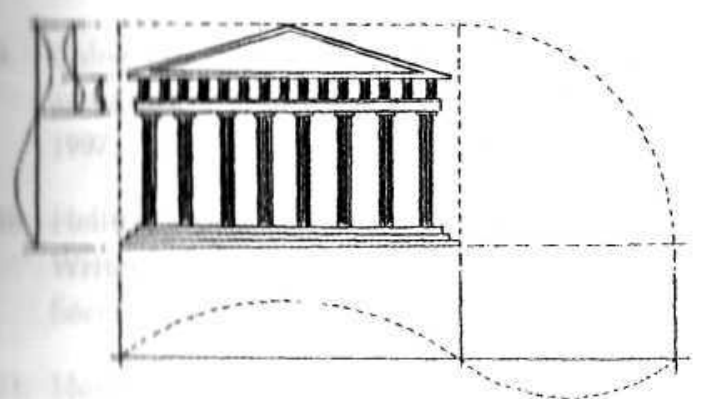

Nig 44-Greek Temple, Parthenon, Greece

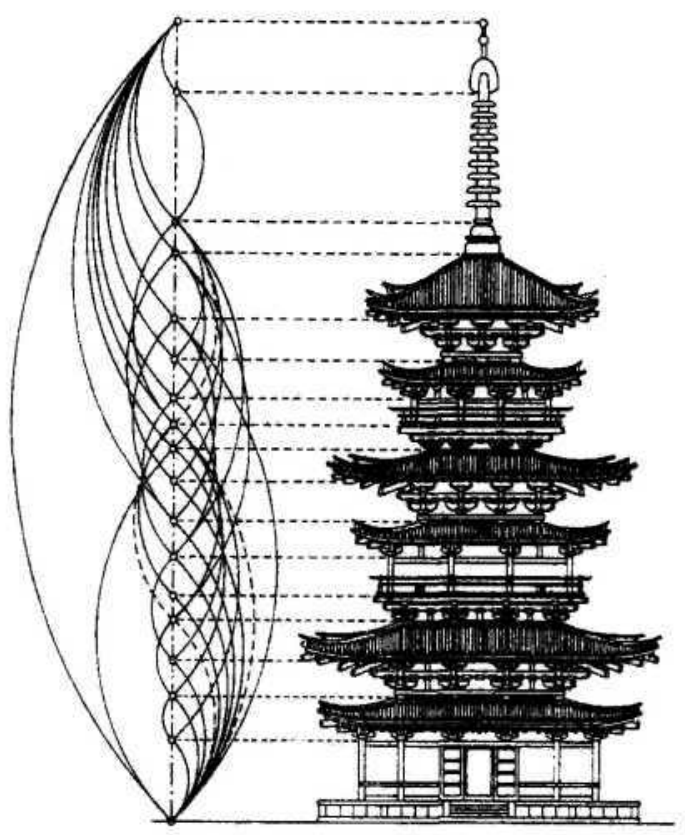

Fig. 45- Yakushi Temple Pagoda, Japan 

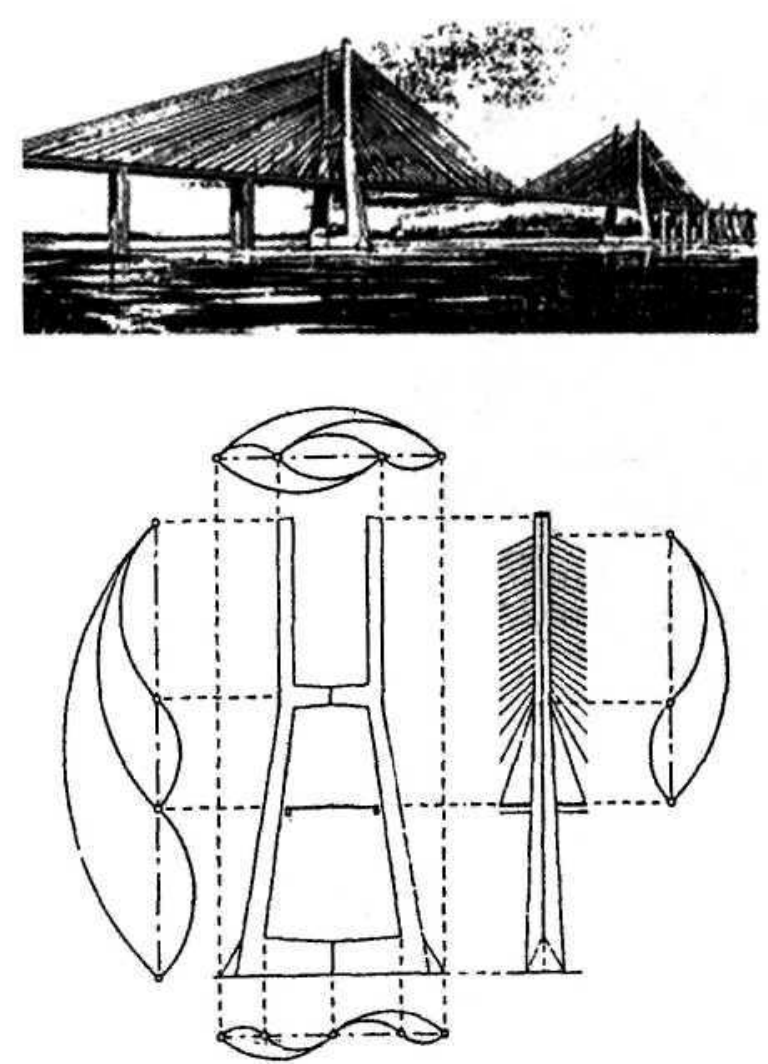

Fig, 46 -Golden Proportion of the Pylons of the Vasco da Gama Bridge

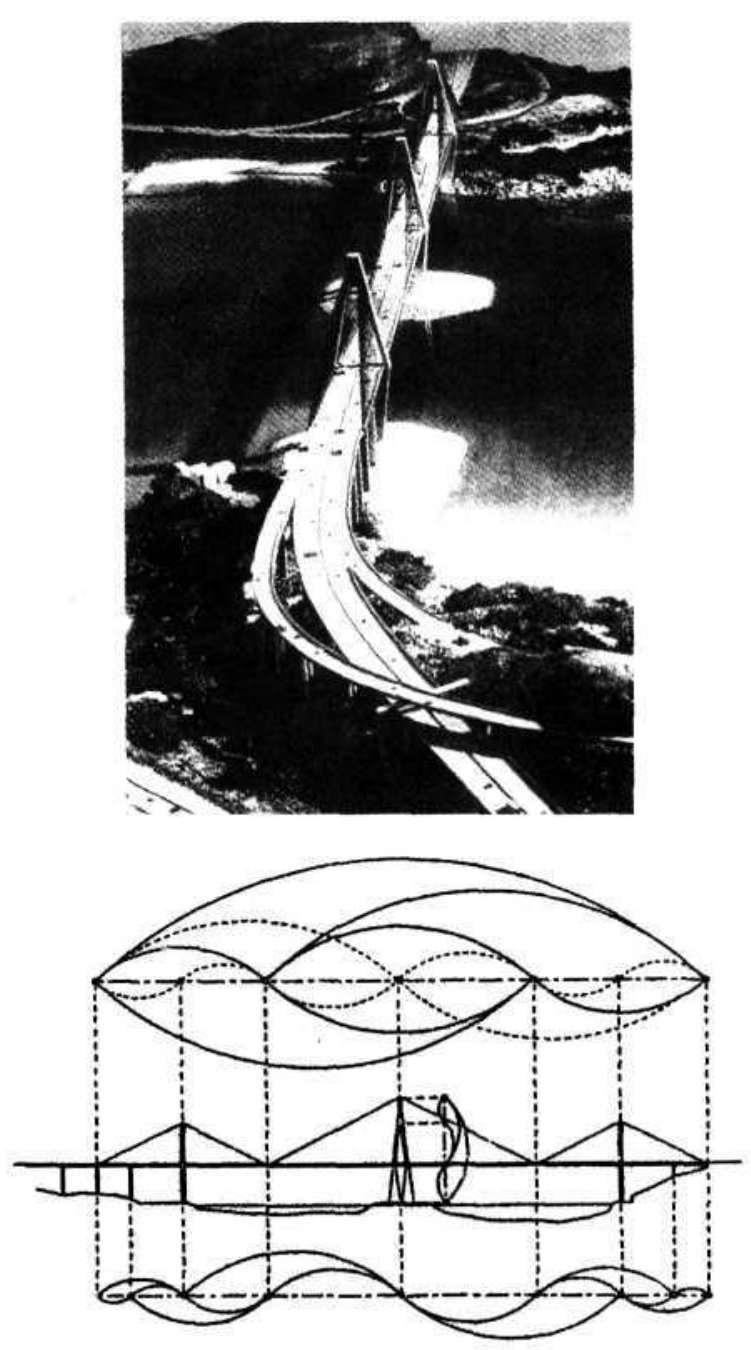

Fig. 47- Golden Proportions of the Ting Kau Bridge

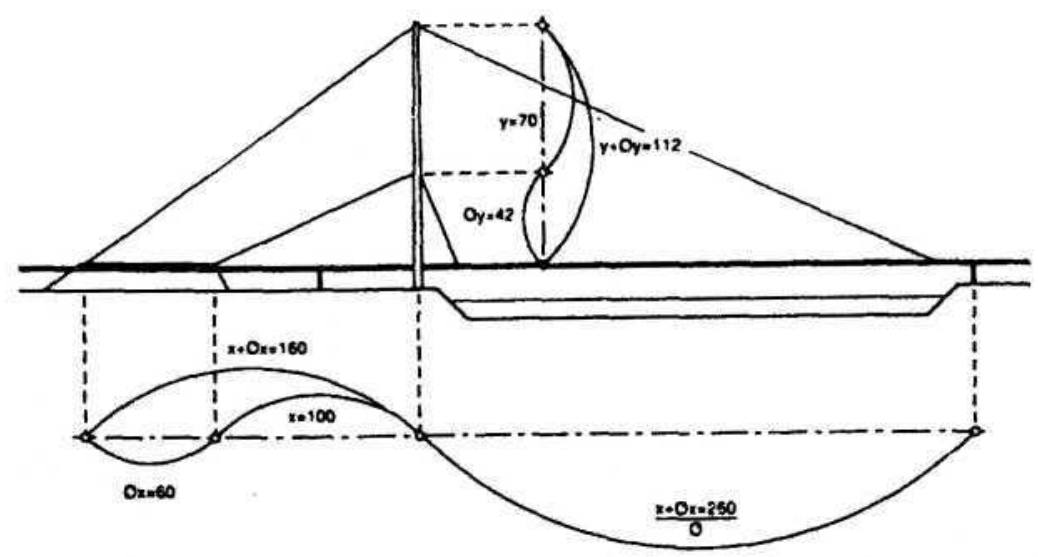

Fig. 48 - Golden Proportion of the Rama VIII Bridge 


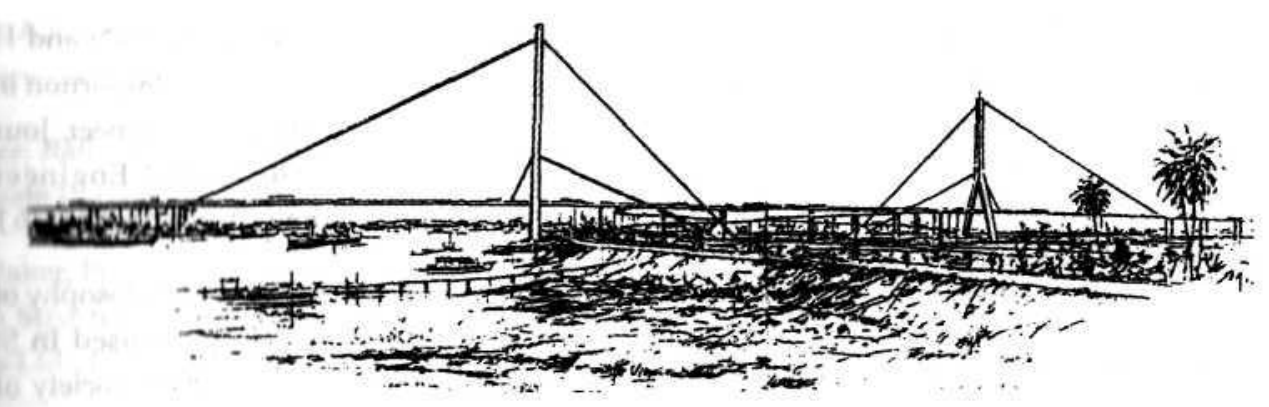

Fig. 49- Proposed Chao Phraya Bridge

\section{Heferences}

I Eulasuilya, C with Dias, WPS and Hettiarchchi MIT I he Aesthetics of Proportion in Structural Tami The Structural Engineer, Journal of The Inatifution of Structural Engineers, United Kingdom, Volume 80-Number 14, 16 July 2002.

1. Kulasuriya، Chandana: "Philosophy of Aesthetics - PropolI loning Systems used in Structures", Question Time - May 2001, Society of Structural Ingineers, Sri Lanka, 2001.

1. "I a vi lep" I Lit Britannica - Vol. 1", Encyclopedia, Britannica. Inc., USA, 1995

4. G. ling A.C.: "Philosophy", Oxford University T歱, UK, 1998

- Eyuayukalov; H.I and Yakovleva, L.A.: A "I indbooh of Philosophy", Progress Publishes, Maicowi 1988

6. Mann James W: Aesthetics - "Exploration in Milesophy", M.E. Sharpe, Inc., New York, 1998.

7. Biteppard, Anne: "Aesthetics - An Introduction to ihe Philesophy of Art", Oxford University Press, $\mathrm{UK}, 1987$.

- Ting Francis, D.K.: "A Visual Dictionary of An I..... ture", John Wiley \& Sons, Inc., New York, 1997 .

4. Ching Prancis, D.K.: "Architecture - Form, Space and Order", John Wiley \& Sons, Inc., New York, 1997.

I6 Ilellman Louis : "Architecture for Beginners", Writeri rtiul Readers Publishing Cooperative flociety Limited, London, 1986.

II Howarth Eva : "Crash Course in Architecture", I Luadline Book Publishing PLC, London, 1990.
12. Nuttgens; Patrick : "The World's Great Architecture", The Hamlyn Publishing Group Limited, London, 1980.

13. Beakley; George $\mathrm{C}$ and Chilton, Ernest G: "Design - Serving in the needs of man", Macmillan Publishing Co. Inc., New York, 1974

14. Reekie; R. Fraser: "Design in the Built Environment", Edward Arnold Publishes Ltd, London, 1972.

15. Wittkower: Rudolf: "Architectural Principles", Weatherb Woolnough Ltd., Northants, 1971.

16. Isaac; A.R.G.: “Approachto Architectural Design", Butterworth^^Co. (Publishes) Ltd., London, 1971.

17. Weber; Ralf: "On the Aesthetics of Architecture", Ashgate Publishing Limited, England, 1995

18. Sandaker; Bjorn Normann and Eggen; Ame Peter: "The Structural Basis of Architecture", Phaidon Press Ltd., London, 1993.

19. Macdonald; Angus J: "Structure \& Architecture", Architectural Press, Elsevier Science Ltd., Oxford, 2001.

20. Holgate; Alan: "Aesthetics of Built Form", Oxford University Press, New York, 1992.

21. Holgate; Alan: "The Art in Structural Design", Oxford University Press, New York, 1986.

22. Salvadori; Mario: "Structure in Architecture", Prentice-Hall Inc., New Jersey, 1963.

23. Salvadori; Mario: "Why buildings stand Up", WW Norton \& Company, Inc., New York, 1990.

24. Orton, Andrew: "The way we build now", E \& FN Spon, London, 1994. 
25. Underwood; James R \& Chiuini; Michele: "Structural Design - A Practical Guide for Architects", John Wiley \& Sons Inc., New York, 1998.

26. Gottemoeller; Freerick: “Bridgescape”,John Wiley \& Sons Inc., New York, 1998.

27. Davis; Colin: "High Tech Architecture", Thames and Hudson Ltd., London, 1988.

28. Slessor; Catherine: "Eco Tech"; Thames and Hudson Ltd., London, 1997.

29. Smith; Bryan Stafford and Coull, Alex: "Tall Building Structures - Analysis \& Design", John Willey \& Sons Inc., New York, 1991.

30. Armstrong; Paul J: "Architectureof Tall Buildings", McCraw-Hill Inc., New York, 1995.

31. Subramanian, N: "Principles of Space Structures", AH Wheeler \& Co. Pte Ltd., 1983.

32. Law; Frederick M: "Thinking Aesthetically is a part of Structural Engineering", Proceedings of the National Structural Engineering Conference, American Society of ivil Engineers, 1976.

33. Faber; Oscar: "The Aesthetic aspects of Civil Engineering Design", The Institution of Civil Engineers, London, 1975.

34. Owens; Graham W and Knowles; Peter R: "Steel Designers' Manual", Blackwell Scientific Publications, London, 1992.

35. Reid; Esmond: "Understanding Buildings", Longman Scientific \& Technical, Essex, 1984.

36. Bennett, David: "The Architecture of Bridge Design", Thomas Telford Publishing, UK,1997.

37. Yee; R and Stanley; R.P.: "The Golden Proportion and its use in the Aesthetic Design of Bridges", Proceeding of Institution of Civil Engineers, 1997.

38. Leonhardt; Fritz: "Bridges - Aesthetics and Design", The Architectural Press Ltd., Lndon, 1982

39. Mutulka; Denise I: "Principles of Design", http:/ Lpicturingbooks.imsignaginarylands .org/palette/design/ principles.html\#harvar

40. Fischer; Robert E: "Architectural Engineering", McGraw-Hill Book Company, New York, 1964.
41. Kulasuriya, $\mathrm{C}$ with Dias, WPS and Hettiarchchi MTP : "The Aesthetics of Proportion in Structural Form" , The Structural Engineer, Journal of The Institution of Structural Engineers, United Kingdom, Volume 80-Number 14, 16July 2002.

42. Kulasuriya, Chandana : Philosophy of Aesthetics \& Proportioning Systems used in Structures", Question Time - May 2001, Society of Structural Engineers, Sri Lanka, 2001.

43. "Encyclopedia, Britannica - Vol. 1", Encyclopedia, Britannica, Inc., USA, 1995

44. Grayling; A.C.: "Philosophy", Oxford University Press, UK, 1998

45. Syusyukalov; B.I and Yakovleva, L.A.: A "Handbook of Philosophy", Progress Publishes, Moscow, 1988

46. Manns; James W: Aesthetics - "Exploration in Philosophy", M.E. Sharpe, Inc., New York, 1998.

47. Sheppard, Anne: "Aesthetics - An Introduction to the Philosophy of Art", Oxford University Press, UK, 1987.,

48. Ching; Francis, D.K.: "A Visual Dictionary of Architecture", John Wiley \& Sons, Inc., New York, 1997.

49. Ching; Francis, D.K.: "Architecture - Form, Space and Order", John Wiley \& Sons, Inc., New York, 1997.

50. Hellman; Louis : "Architecture for Beginners", Writers and Readers Publishing Cooperative Society Limited, London, 1986.

51. Howarth; Eva : "Crash Course in Architecture", Headline Book Publishing PLC, London, 1990.

52. Nuttgens; Patrick : "The World's Great Architecture", The Hamlyn Publishing Group Limited, London, 1980.

53. Beakley; George $\mathrm{C}$ and Chilton, Ernest G: "Design - Serving in the needs of man", Macmillan Publishing Co. Inc., New York, 1974

54. Reekie; R. Fraser: "Design in the Built Environment", Edward Arnold Publishes Ltd, London, 1972.

55. Wittkower: Rudolf: "Architectural Principles", Weatherb Woolnough Ltd., Northants, 1971. 
56. Laae A.R.( :. "Approach to Architectural Design", liulter worth ^ Co. (Publishes) Ltd., London, 1971.

If Weber Ralf: "On the Aesthetics of Architecture", Ashgate Publishing Limited, England, 1995

36. flandaker, Bjorn Normann and Eggen; Ame Peter: "I lii Btruitural Basis of Architecture", Phaidon Fress Itd., London, 1993.

1ft Mardonald. Angus J: "Structure \& Architecture", An hiltertural Press, Elsevier Science Ltd., Oxford, 2001

M Holgate, Alan "Aesthetics of Built Form", Oxford University Press، New York, 1992.

61. Holgate; Alan: "The Art in Structural Design", 1. ..... I IIniversity Press, New York, 1986.

62. Galvadori Mario: "Structure in Architecture", Pin nilie I Iall Inc., New Jersey, 1963.

M Elalvadori Mario: "Why buildings standUp",WW Nerton ft 1 ompany, Inc., New York, 1990.

M Orion, Andrew: "The way we build now", E \& FN Bpon, London, 1994.

M Underwood; James R \& Chiuini; Michele: "Grruitural Design - A Practical Guide for Architects", John Wiley \& Sons Inc., New York, 1098

M1 Dlettemoeller; Freerick : Bridgescape. John Wiley * Gona Inc., New York, 1998.

67. Davis; Colin: "High Tech Architecture", Thames and I ludson Ltd., London, 1988.

M Elessor; Catherine: "Eco Tech"; Thames and Ifudson Ltd., London, 1997.
69. Smith; Bryan Stafford and Coull, Alex: "Tall Building Structures - Analysis \& Design", John Willey \& Sons Inc., New York, 1991.

70. Armstrong; Paul J: "Architecture of Tall Buildings", McCraw-Hill Inc., New York, 1995.

71. Subramanian, N: "Principles of Space Structures", AH Wheeler \& Co. Pte Ltd., 1983.

72. Law; Frederick M: "Thinking Aesthetically is a part of Structural Engineering", Proceedings of the National Structural Engineering Conference, American Society of ivil Engineers, 1976.

73. Faber; Oscar: "The Aesthetic aspects of Civil Engineering Design", The Institution of Civil Engineers, London, 1975.

74. Owens; Graham W and Knowles; Peter R: "Steel Designers' Manual", Blackwell Scientific Publications, London, 1992.

75. Reid; Esmond: "Understanding Buildings", Longman Scientific \& Technical, Essex, 1984.

76. Bennett, David: "The Architecture of Bridge Design", Thomas Telford Publishing, UK,1997.

77. Yee; R and Stanley; R.P.: "The Golden Proportion and its use in the Aesthetic Design of Bridges", Proceeding of Institution of Civil Engineers, 1997.

78. Leonhardt; Fritz: "Bridges - Aesthetics and Design", The Architectural Press Ltd., Lndon, 1982.

79. Mutulka; Denise I: "Principles of Design", http:/. Lpicturingbooks.imsignaginarylands .org/palette/design/ principles.html\#harvar

80. Fischer; Robert E: "Architectural Engineering", McGraw-Hill Book Company, New York, 1964. 